\title{
Variation in body size and life history traits in Drosophila aldrichi and D. buzzatii from a latitudinal cline in eastern Australia
}

\author{
VOLKER LOESCHCKE* ††, JøRGEN BUNDGAARD †† \& J. S. F. BARKER \\ $\dagger$ Department of Ecology and Genetics, Ny Munkegade Bldg 540, University of Aarhus, DK 8000 Aarhus C, Denmark, \\ $\$$ Division of Animal Science, University of New England, Armidale, NSW 2351, Australia
}

Latitudinal variation in thorax and wing size traits was studied in wild-caught flies of the cactophilic Drosophila species, D. aldrichi and D. buzzatii, and their laboratory-reared progeny. The flies originated from five populations in Queensland, Australia, spanning an 800-km transect. The laboratory flies were reared at controlled densities and three temperatures, 20,25 , and $30^{\circ} \mathrm{C}$. We measured the same traits for the laboratory-reared flies as for the wild-caught flies, plus developmental time and viability. Latitudinal variation in wild-caught flies of both species followed a similar pattern for all linear size traits, with size generally increasing from north to south, but with flies from one intermediate locality markedly smaller. A drier environment at this locality and weather conditions immediately prior to collection, most likely explain the reduced size. Laboratory-reared D. aldrichi from this locality also were smaller than those from other localities, and had the fastest developmental time and highest viability. In laboratory-reared flies, body size traits did not show any clear trend to increase with latitude. The patterns of change with latitude were different between species, with $D$. aldrichi more similar in pattern to that of the natural populations. D. aldrichi had comparatively higher coefficients of variation in the laboratory-reared flies and lower viability at all temperatures. However, fluctuating asymmetry was lower in D. aldrichi in both wild-caught and laboratory-reared flies. The differences among populations of $D$. aldrichi for all traits were much larger than for $D$. buzzatii. As these differences in the laboratory-reared flies are expected to be largely genetic, they most likely reflect adaptation to specific (unknown) environmental factors that do not show linear latitudinal variation on the geographical scale studied.

Keywords: developmental temperature, fluctuating asymmetry, latitudinal variation, phenotypic plasticity, thorax size, wing size.

\section{Introduction}

Many species show variation in quantitative traits related to latitude, and such variation has often been attributed to adaptation to different environmental conditions, with temperature or temperature-related factors being considered as the main agents of selection. For endotherms, the relationship between volume and surface area gives a good explanation why organisms are generally smaller towards the equator. For ectotherms, a similar relationship of decreasing body size towards the equator has often been reported, but no generally accepted explanation of latitudinal variation in size related traits has yet been found for this group of organisms. In Drosophila, latitudinal variation has been

*Correspondence. E-mail: volker.loeschcke@biology.au.dk found in morphological traits including wing length, wing area and thorax length (David et al., 1983; Capy et al., 1993; Barker \& Krebs, 1995), and in reproductive traits such as ovariole number (Delpuech et al., 1995; Starmer et al., 1997).

Geographic variation in itself is no proof for natural selection, as drift and gene flow also may shape a pattern of clinal variation. However, many of the clines seen in Drosophila have been reported from different continents, with the same direction of change in each - body size increasing away from the equator (see James et al., 1995; van 't Land et al. 1999, and references therein). Also, populations of Drosophila maintained in the laboratory for many generations have evolved into a smaller size at higher temperatures (Cavicchi et al., 1989; Partridge et al., 1994), suggesting that adaptation to temperature is at least partly responsible for the clinal 
variation in body size. As a number of life history traits have shown genetic correlation with body size (see Roff \& Mousseau, 1987; van 't Land et al. 1999 for references), clinal variation in body size may also correspond to variation in other life history traits. James \& Partridge (1995) found that developmental time of D. melanogaster (at $18^{\circ} \mathrm{C}$ in the laboratory) decreased significantly with latitude. For these same populations, James et al. (1995) found body size to increase with latitude but that among populations body size was not associated with developmental time. In South American populations of D. melanogaster, however, although wing length and wing area showed a significant positive correlation with latitude, the correlation between developmental time and latitude was not significant (van 't Land et al. 1999). Nevertheless, within populations, short developmental time and small body size generally are genetically correlated (Nunney, 1996).

Another way of responding to environmental variation in temperature is by phenotypic plasticity. There is ample plasticity for body size traits in various species of Drosophila (David et al., 1994), including D. aldrichi and D. buzzatii (Barker \& Krebs, 1995; Loeschcke et al., 1999), with adult flies generally decreasing in size with increasing rearing temperatures. At the lowest end of the temperature scale, thorax and wing length may fall below their maximum size, with temperature at maximum thorax length being different from temperature at maximum wing length (Morin et al., 1997; Loeschcke et al., 1999). Size traits of flies caught in the field additionally may be affected by the resources available for larvae (Thomas, 1993).

Here we study latitudinal variation of several thorax and wing size traits in populations of two species, D. aldrichi and D. buzzatii, originating from five Australian localities of coexistence along a north-south transect spanning $800 \mathrm{~km}$. These are cactophilic species that feed and breed in rotting cladodes of Opuntia spp. They overlap in their distributions along this transect, but $D$. aldrichi is more common in the north than D. buzzatii, and is absent to the south of this transect. Thus the northernmost population is at the northern edge of the distribution of D. buzzatii while the southernmost population is at the distributional edge of D. aldrichi. Populations along this transect are exposed to, and presumably adapted to different climatic regimes, and the populations of each species may be expected to contrast in their reaction to varying temperatures in the laboratory.

\section{Materials and methods}

\section{Field collections}

Along a latitudinal transect in Queensland spanning nearly $800 \mathrm{~km}$, populations of D. aldrichi and D. buzzatii were collected from five localities numbered 1-5 from

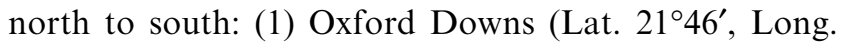
$148^{\circ} 51^{\prime}$ ), (2) Gogango Creek (Lat. 234', Long. $150^{\circ} 10^{\prime}$ ), (3) Wahruna (Lat. $25^{\circ} 12^{\prime}$, Long. $151^{\circ} 10^{\prime}$ ), (4) Binjour (Lat. $25^{\circ} 31^{\prime}$, Long. $151^{\circ} 27^{\prime}$ ), and (5) Grandchester (Lat. 27 $41^{\prime}$, Long. 152 $27^{\prime}$ ). These localities were chosen to represent the northernmost known permanent population of D. buzzatii and the southernmost known permanent population of $D$. aldrichi, with localities generally similar distances apart, and generally decreasing in temperature (Table 1). Flies were sexed and counted in the field and brought to the laboratory together with some field-collected rots (Table 2).

\section{Experimental design}

The wild-collected flies were used to start mass populations, being put into a maximum of 10 bottles per population. Individuals from populations with low numbers of founder individuals were transferred once to new bottles, and where available, emergences from rots collected in the field were added to these bottles

Table 1 Distances between localities, Opuntia species, mean annual temperatures, maximum and minimum temperatures $\left({ }^{\circ} \mathrm{C}\right)$ in January and July, and annual rainfall $(\mathrm{mm})$, estimated using the BIOCLIM package (Nix, 1986)

\begin{tabular}{|c|c|c|c|c|c|c|c|c|}
\hline \multirow{2}{*}{$\begin{array}{l}\text { Locality } \\
\text { (north to south) }\end{array}$} & \multirow{2}{*}{$\begin{array}{l}\text { Distance }(\mathrm{km}) \text { from } \\
\text { previous locality }\end{array}$} & \multirow{2}{*}{ Opuntia sp. } & \multicolumn{5}{|c|}{ Temperature $\left({ }^{\circ} \mathrm{C}\right)$} & \multirow{2}{*}{$\begin{array}{l}\text { Rainfall } \\
(\mathrm{mm})\end{array}$} \\
\hline & & & Annual & \multicolumn{2}{|c|}{ Max. } & \multicolumn{2}{|c|}{ Min. } & \\
\hline 1 Oxford Downs & & O. tomentosa & 22.2 & 32.0 & 22.5 & 21.0 & 9.4 & 812 \\
\hline 2 Gogango Creek & 260 & O. streptocantha & 21.7 & 31.9 & 21.7 & 21.6 & 8.4 & 741 \\
\hline 5 Grandchester & 271 & $\begin{array}{l}\text { O. tomentosa, } \\
\text { O. stricta }\end{array}$ & 19.5 & 30.7 & 20.2 & 19.2 & 5.3 & 838 \\
\hline
\end{tabular}


Table 2 Numbers of females and males of D. aldrichi and D. buzzatii caught in the wild, numbers used to start mass populations, and numbers emerging from rots (in parentheses) that were added to the mass populations to increase effective sizes

\begin{tabular}{|c|c|c|c|c|c|c|c|c|}
\hline \multirow[b]{3}{*}{ Locality } & \multicolumn{4}{|c|}{ D. aldrichi } & \multicolumn{4}{|c|}{ D. buzzatii } \\
\hline & \multicolumn{2}{|c|}{ Wild-caught } & \multicolumn{2}{|c|}{ Population } & \multicolumn{2}{|c|}{ Wild-caught } & \multicolumn{2}{|c|}{ Population } \\
\hline & Males & Females & Males & Females & Males & Females & Males & Females \\
\hline Oxford Downs & 54 & 68 & 49 & 64 & 1 & 3 & $1(4)$ & $3(3)$ \\
\hline Gogango Creek & 12 & 10 & $10(2)$ & $6(1)$ & 143 & 88 & 90 & 90 \\
\hline Wahruna & 25 & 30 & 22 & 26 & 116 & 96 & 90 & 95 \\
\hline Binjour & 284 & 259 & 168 & 166 & 237 & 190 & 150 & 150 \\
\hline Grandchester & 4 & 5 & 3 & 5 & 380 & 413 & 200 & 150 \\
\hline
\end{tabular}

(Table 2). After egg laying, flies were anaesthetized to measure thorax length and wing dimensions of the wildcaught flies for up to 50 individuals per species, sex and population.

The mass populations were maintained for four generations (10 bottles/population, 20 pairs/bottle) at $25^{\circ} \mathrm{C}$ on a cactus-yeast-sucrose medium (Starmer \& Barker, 1986). Progeny of the fourth generation were stored on medium seeded with live yeast (10 bottles/ population, 50 pairs/bottle). After two transfers to fresh bottles at three-day intervals, these flies were transferred on day 7 after emergence to new bottles containing a 5 -mL spoon with yeast paste. Twenty to $24 \mathrm{~h}$ later, the eggs were washed from the yeast paste and transferred to Petri dishes containing $1.5 \%$ agar. Next morning, newly emerged larvae ( $\geq 2$-h-old) were collected into vials (30 per vial) with $7 \mathrm{~mL}$ cactus-yeast-sucrose medium. After larval collection, 10 vials per population of each species were synchronously put at three temperatures, 20,25 and $30^{\circ} \mathrm{C}$. Emerging flies were collected daily and stored in vials with medium at $18^{\circ} \mathrm{C}$. From days with peak emergence, three individuals of each sex from each vial were randomly chosen for measuring thorax length and wing dimensions.

\section{Characters measured and parameters estimated}

Thorax length (anterior margin of the thorax to the posterior tip of the scutellum) was measured using a binocular microscope with a digital filar eyepiece (Los Angeles Scientific Instrument Company, Inc.), which logged measurements (in micrometers) directly to a PC. Both wings were mounted on a microscope slide with a drop of water. Wings were projected using a WILD binocular microscope onto a Houston Instrument HIPAD digitizer, and six points recorded (Fig. 1), with point co-ordinates transferred to a microcomputer using the program DIGITIZE. A second program, DISTANCE, was used to convert the point coordinates to linear

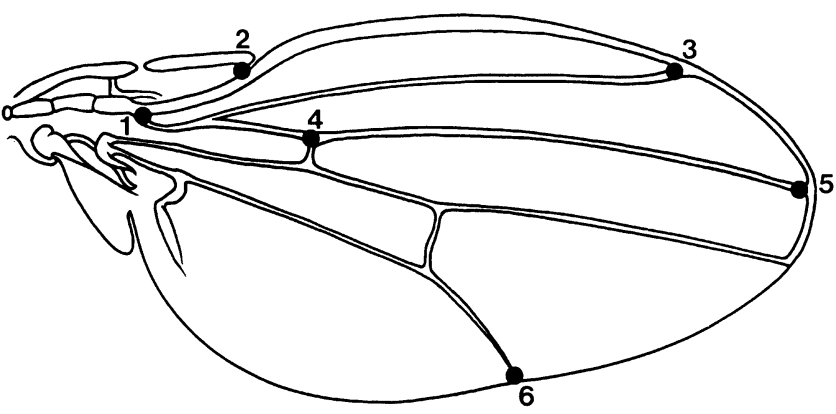

Fig. 1 Drosophila wing showing the six points whose co-ordinates were recorded.

measurements, namely: (i) second longitudinal vein length (L2) = distance from point 1-3; (ii) proximal length of third longitudinal vein $(\mathrm{L} 3 \mathrm{p})=$ distance from point 1-4; (iii) distal length of third longitudinal vein (L3d) $=$ distance from point 4-5; (iv) third longitudinal vein length $(\mathrm{L} 3)=$ distance from point $1-5$; (v) wing width $1(\mathrm{~W} 1)=$ distance from midpoint of 2 and 3-6; (vi) wing width $2(\mathrm{~W} 2)=$ distance from point $2-6$; and (vii) Wing width $3(\mathrm{~W} 3)=$ distance from point $3-6$. From these linear measurements, wing area was estimated as $(\mathrm{W} 1 \times \mathrm{L} 3) / 2$, wing shape as $\mathrm{L} 3 / \mathrm{W} 1$ and wing vein length ratio as L3d/L3p. Finally, the ratio L3/thorax length was used as an index of wing loading.

\section{Statistical analyses}

All traits were $\log _{10}$ transformed (Thomas \& Barker, 1993) to eliminate the statistical problems arising from ratio measures (Atchley et al., 1976). For analyses of variance, all effects were fixed: species, population, temperature and sex. ANOVA were performed using the GLM procedure of SAS (SAS Institute, 1989). Normality of residuals in all ANOvA was tested using the SAS UNIVARIATE procedure (SAS Institute, 1985). In analyses of the natural population data, all traits except wing 
loading index, wing shape and vein ratio in both species, L3d in D. aldrichi and L3p in D. buzzatii showed significant deviations from normality. In the overall analysis of the laboratory data, L3d showed significant deviations from normality, as did L2, L3 and L3d for D. aldrichi, and L2 for D. buzzatii in the separate ANOvA for each species, primarily a consequence of outliers. As deletion of outliers made no difference to the results of the $F$-tests, and as ANOvA is robust to deviations from normality, all data were retained in the analyses.

\section{Plasticity}

Plasticity was evaluated by plotting reaction norms for each trait in each species as means of each population at each temperature. Effects of temperature on the phenotypic variation of each trait were considered by estimating the coefficient of variation $\left(\mathrm{CV}^{*}-\right.$ bias corrected; Sokal \& Rohlf, 1981; p. 59) from the mean and SD of the individual flies measured for each species $\times$ population $\times$ temperature $\times$ sex, and ANOVA of these data performed using the same specification of effects as in the ANOvA of individual measurements.

\section{Asymmetry}

Fluctuating asymmetry was estimated as Index 4 of Palmer \& Strobeck (1986), i.e. $\operatorname{var}\left(A_{\mathrm{i}}\right)$, where $A_{\mathrm{i}}$ is the difference between sides for each individual. $\operatorname{var}\left(A_{\mathrm{i}}\right)$ was estimated as $(2 \times$ Error MS) from the separate ANOVA (two sides, 30 individuals) for each species $\times$ population $\times$ temperature $\times$ sex combination.

\section{Results}

\section{Latitudinal variation}

Natural populations For all linear body size dimensions averaged over sexes, the species showed parallel changes with latitude (Fig. 2), except for thorax length and wing loading index at localities 1 and 2. However, the interaction for species $\times$ population (latitude) was significant only for the wing loading index. The species were significantly different (D. buzzatii larger) for the wing length traits (except L3p), wing shape and vein ratio. Sex was significant for all linear traits and wing area (females larger).

In separate ANOVA for each species, populations were significantly different for all traits except wing shape and vein ratio in $D$. buzzatii, but only for thorax length, L2, L3p, wing loading index and vein ratio in $D$. aldrichi. For all linear traits in both species, values generally increased from north to south, but were clearly smallest for locality 2 (Fig. 2).
For all traits, there was no significant relationship between trait size and asymmetry (R-L). Tests of deviation from zero mean of (R-L) (directional asymmetry) showed that over all 10 traits, 13 (of $174=7.5 \%$ ) were significant $(8 \mathrm{R}>\mathrm{L}, 5 \mathrm{R}<\mathrm{L})$. The numbers of significant tests for each trait did not differ significantly. Species and populations did not differ in numbers of significant tests, but the number of significant tests was significantly $(P<0.05)$ greater for males $(11)$ than for females (2). Over the 10 traits (160 tests), 5.6\% showed significant departures from normality, but the proportions of significant tests were not different among traits, species, populations or sexes. Of the nine significant departures from normality, five (all for D. buzzatii, two for L3d, and one each for W2, W3 and wing area) showed significant negative kurtosis, indicating antisymmetry. Significant effects on FA were found for species for all traits except L3p, W1 and wing area, with FA in $D$. aldrichi less than in D. buzzatii for all traits.

Experimental populations In the ANOVA including species (not shown), the main effects species, population, temperature and sex, and the interactions species $\times$ population and species $\times$ temperature were significant for all traits (except sex for vein ratio, and species $\times$ temperature for thorax length and viability). However, separate ANOva for each species (Tables 3, 4, $5,6)$ are more informative, particularly for the population-temperature interaction (plasticity).

For D. aldrichi, populations and temperatures were significantly different for all traits (Tables 3, 4; Fig. 3). Plasticity resulting from temperature was significantly different for different populations (significant population-temperature interaction) for some of the wing length and width measures, for all four compound traits and for developmental time.

For D. buzzatii, temperature effects were significant for all traits, but populations were significantly different only for L3d, L3, W1, W2, W3, wing loading index, wing shape, vein ratio and viability (Tables 5, 6; Fig. 3). Population $\times$ temperature was significant only for $\mathrm{W} 1$, W2, wing area, wing shape and developmental time.

Plots of the latitudinal (among population) variation show $D$. buzzatii to be generally larger than $D$. aldrich (Fig. 3). In D. buzzatii, thorax length generally decreased from north to south, but this trend was not significant. L3, L3d, W2 and the wing loading index generally increased from north to south, while W1 and W3 generally decreased.

D. aldrichi showed more variation among populations than D. buzzatii, with differences between maximum and minimum values two to three times larger (Fig. 3), but with no clear latitudinal trend. For thorax length, all linear wing dimensions and wing area, the populations 


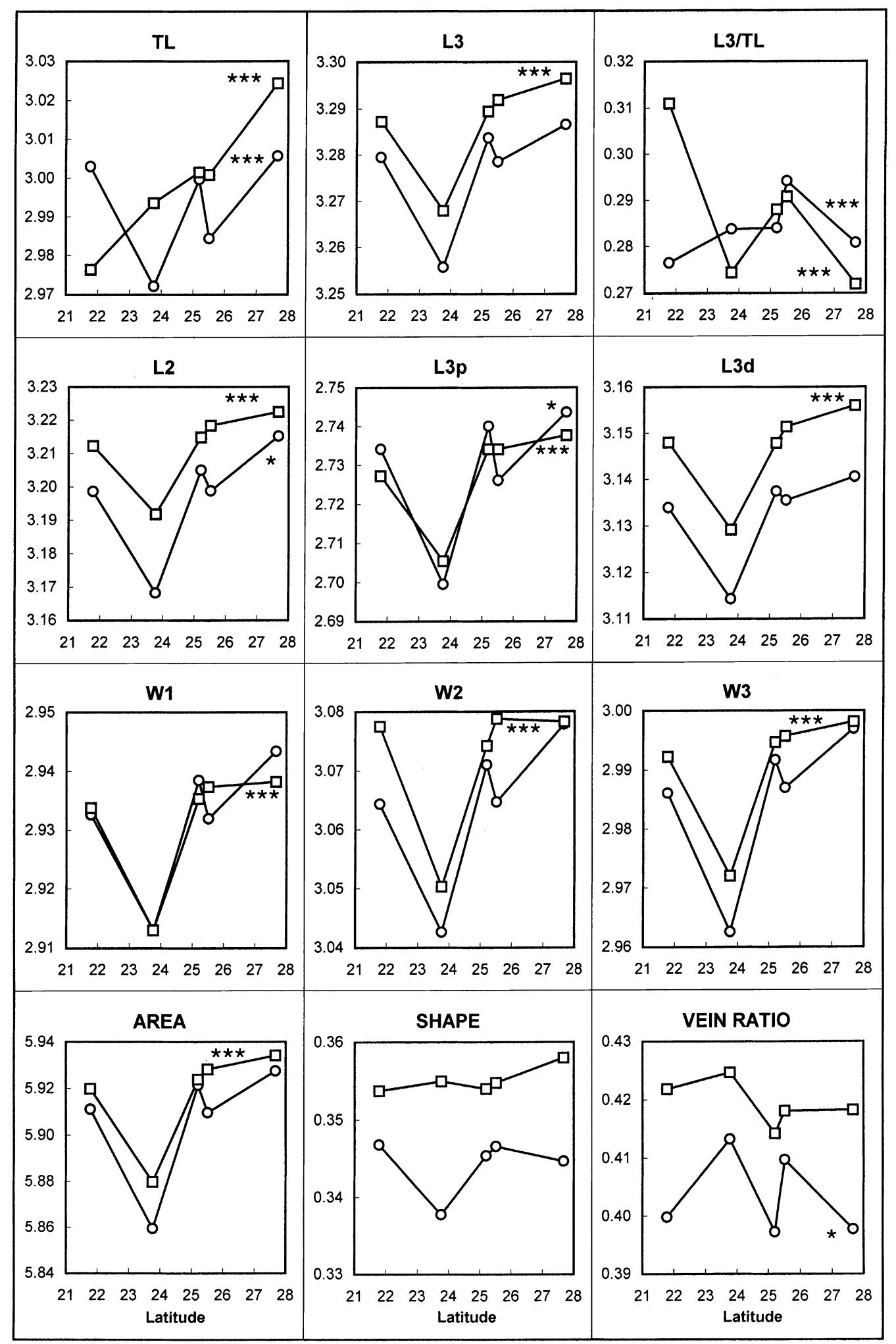

Fig. 2 Variation for each trait ( $\log _{10}$ values) in each species $(\bigcirc=D$. aldrichi, $\square=D$. buzzatii) for the natural populations represented by their latitude. From left to right localities are numbered 1-5 (Oxford Downs, Gogango Creek, Wahruna, Binjour and Grandchester). For explanation of the traits see text. Significant differences among populations are indicated $(* P<0.05$, $* * * P<0.001)$. 


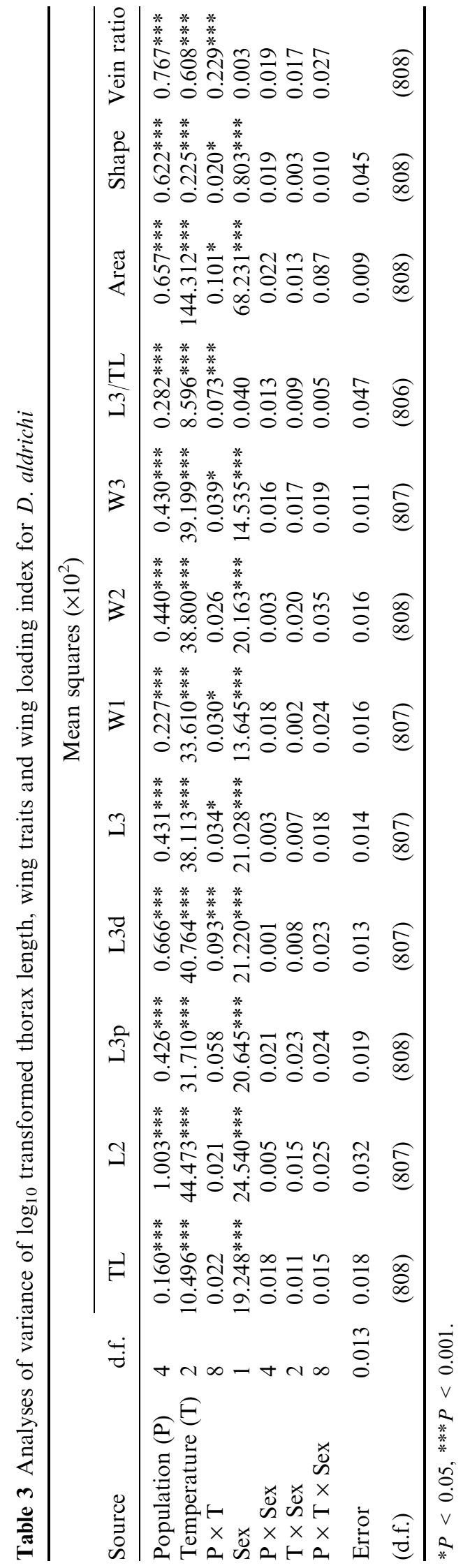

Table 4 Analyses of variance of developmental time and viability for $D$. aldrichi

\begin{tabular}{lrcl}
\hline & & \multicolumn{2}{c}{ Mean squares } \\
\cline { 3 - 4 } Source & d.f. & Devel. time & Viability \\
\hline Population (P) & 4 & $1.334^{* * *}$ & $0.538^{* * *}$ \\
Temperature (T) & 2 & $1004.037^{* * *}$ & $0.177^{* * *}$ \\
$\mathrm{P} \times \mathrm{T}$ & 8 & $0.320^{*}$ & 0.025 \\
Error & 135 & 0.122 & 0.020 \\
\hline
\end{tabular}

${ }^{*} P<0.01,{ }^{* * *} P<0.001$.

originating from the three most northern localities showed a similar pattern of change, with values of the population from locality 2 clearly below those from localities 1 and 3. However, for localities 3, 4 and 5, W1, W3 and wing area are less in 3 than in 4 and 5, while other linear traits show change in size in the opposite direction. These different patterns of size changes with latitude lead to large differences among populations in the compound variables wing loading index, wing shape and vein ratio, with maximum values at locality 4 .

Variations among populations in both viability and developmental time were much greater in $D$. aldrichi at all temperatures, with survival especially low in the populations from localities 1 and 4 and with faster development in the population from locality 2 .

The analysis of variance of the coefficients of variation $\left(\mathrm{CV}^{*}\right)$ estimated from the measurements of individual flies in each species $\times$ population $\times$ temperature $\times$ sex showed significant differences between species for all traits, with values in $D$. aldrichi higher than those for D. buzzatii (results not shown). Also temperature was significant for all traits except for L3p and vein ratio (both $P<0.1$ ), with mean $\mathrm{CV}^{*}$ increasing with increasing temperatures. Population was significant for L3p, L3d and vein ratio, and sex only for wing shape $(P<0.001)$. Species $\times$ population was significant only for $\mathrm{L} 3 \mathrm{~d}, \mathrm{~W} 2$ and vein ratio $(P<0.05)$. Species $\times$ temperature was significant for wing shape and vein ratio (both $P<0.05$ ), with $\mathrm{CV}^{*}$ values increasing with temperature in $D$. aldrichi and with minimum values at the intermediate temperature in D. buzzatii.

\section{Rearing temperatures/reaction norms}

With increasing temperature from 20 to $25-30^{\circ} \mathrm{C}$, all traits except wing shape, vein ratio, developmental time and viability showed a linear decrease, with a steeper slope in D. aldrichi (except thorax length and L3p results not shown). Effects on the compound parameters wing shape and vein ratio and on developmental time and viability, however, were either not linear or differed 


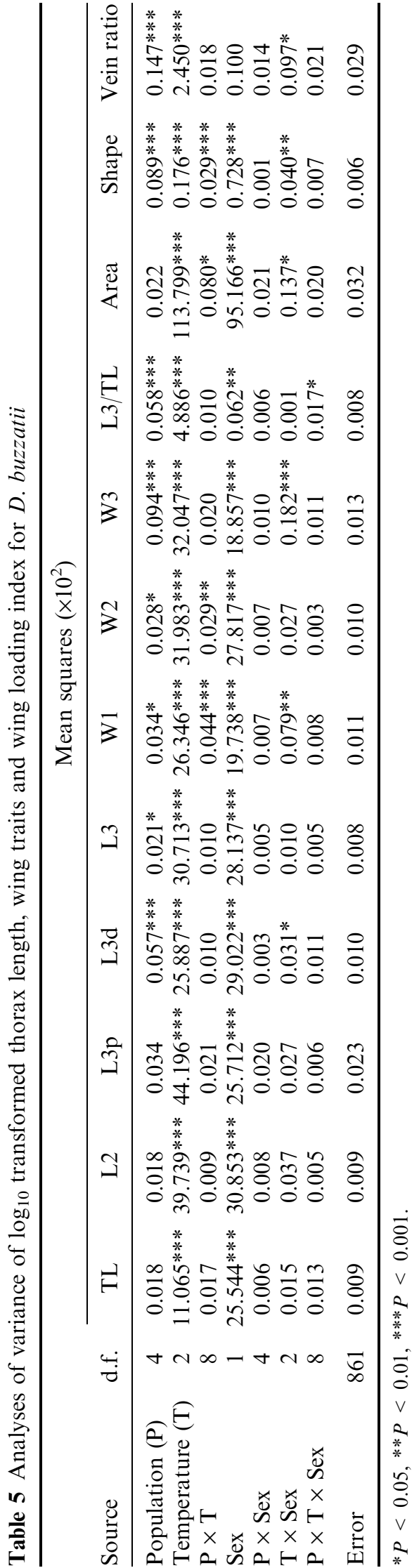

Table 6 Analyses of variance of developmental time and viability for $D$. buzzatii

\begin{tabular}{lrcl}
\hline & & \multicolumn{2}{c}{ Mean squares } \\
\cline { 3 - 4 } Source & d.f. & Devel. time & Viability \\
\hline Population(P) & 4 & 0.115 & $0.059^{* *}$ \\
Temperature(T) & 2 & $882.404^{* * *}$ & $0.416^{* * *}$ \\
$\mathrm{P} \times \mathrm{T}$ & 8 & $0.176^{*}$ & 0.019 \\
Error & 135 & 0.081 & 0.013 \\
\hline
\end{tabular}

$* P<0.05, * * P<0.01, * * * P<0.001$.

in direction. Wing shape decreased in D. buzzatii with increasing temperature, but was at a maximum at $25^{\circ} \mathrm{C}$ in $D$. aldrichi, whereas vein ratio decreased with increasing temperature in $D$. aldrichi but increased in D. buzzatii. Developmental time was about half a day shorter in D. buzzatii at 20 and $25^{\circ} \mathrm{C}$, but slightly longer at $30^{\circ} \mathrm{C}$, with means of $17.57,11.45$ and 9.52 days, respectively, as compared with $18.15,11.93$ and 9.46 in D. aldrichi. Viability at all temperatures was higher in D. buzzatii, with means of $0.84,0.82$ and 0.67 , respectively, as compared with $0.71,0.68$, and 0.59 in D. aldrichi.

\section{Asymmetry}

For all traits, there was no significant relationship between trait size and asymmetry (R-L). Over the 10 traits (600 tests), $6.83 \%$ showed significant departures from normality, but no evidence of antisymmetry, and the proportions of significant tests were not different among traits or temperatures, or between the species.

Tests of deviation from zero mean (directional asymmetry) over all traits showed that 65 out of 600 $(10.8 \%)$ tests were significant, with $30 \mathrm{R}>\mathrm{L}$ and 35 $\mathrm{R}<\mathrm{L}$ (not significantly different from 1:1). The numbers of significant tests for each trait did not differ significantly. However, both L3p and W2 showed significant excesses of $\mathrm{R}<\mathrm{L}\left(\chi_{(1)}^{2}=4.5, P<0.05\right.$ and $\chi_{(1)}^{2}=7.0, \quad P<0.01$, respectively), while vein ratio showed a significant excess of $\mathrm{R}>\mathrm{L} \quad\left(\chi_{(1)}^{2}=6.4\right.$, $P<0.05)$. The numbers of significant tests did not differ between the sexes, and within each sex, the proportions of $\mathrm{R}>\mathrm{L}$ and $\mathrm{R}<\mathrm{L}$ did not differ significantly from 1:1. Forty-one tests were significant for $D$. aldrichi and 24 for $D$. buzzatii, significantly different from an expected 1:1 ratio $\left(\chi_{(1)}^{2}=4.446\right.$, $P<0.05)$. Furthermore, this difference between the species is clear for temperature effects, where the numbers of significant tests at 20,25 and $30^{\circ} \mathrm{C}$ were 23, 6 and 12 for D. aldrichi $\left(\chi_{(2)}^{2}=10.875, P<0.01\right)$, and 5, 12, 7 for D. buzzatii (not significantly different 

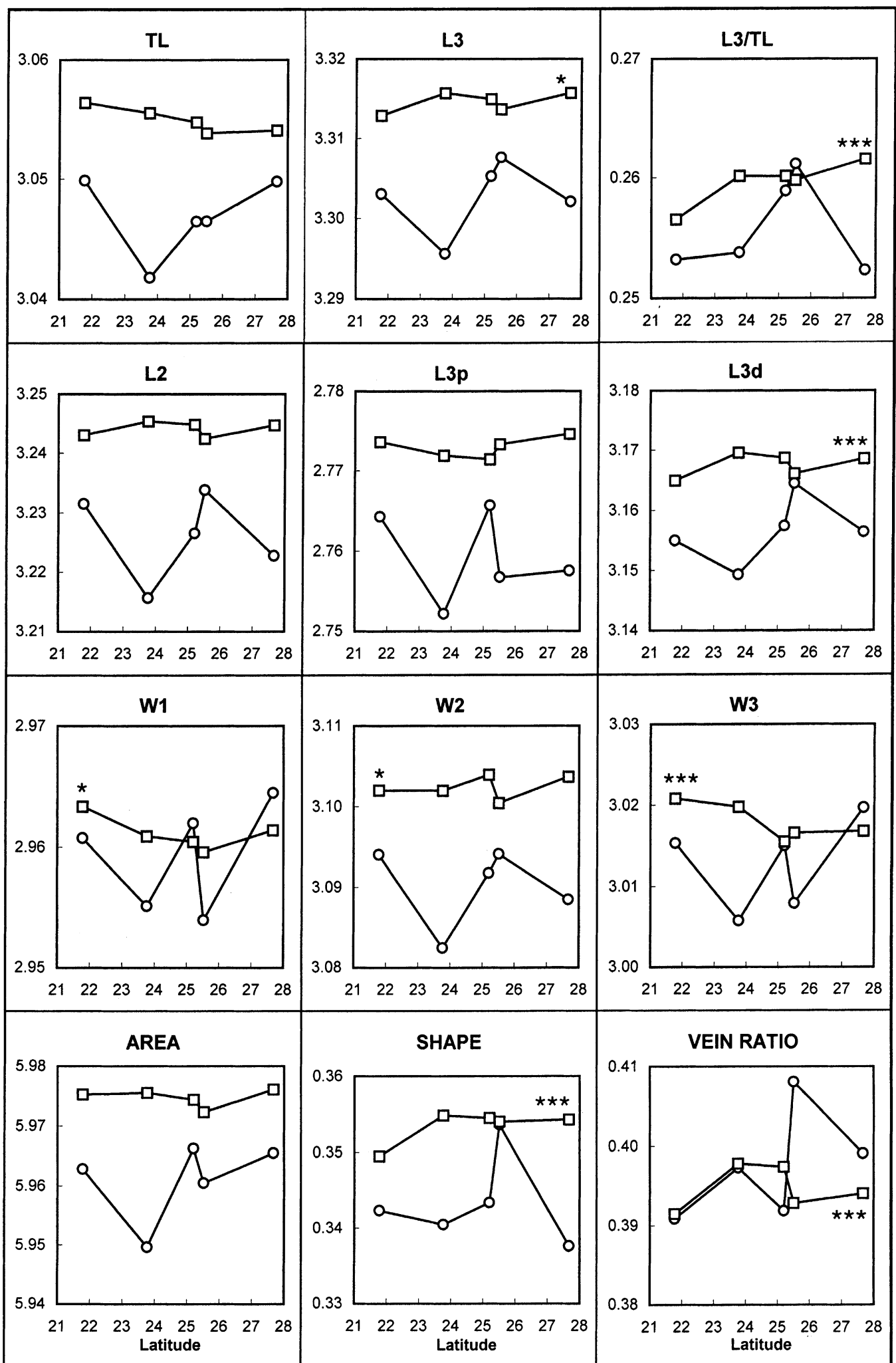

Fig. 3 Variation for each trait $\left(\log _{10}\right.$ values of means over temperatures) in each species $(\bigcirc=D$. aldrichi, $\square=D$. buzzatii) in the experimental populations represented by their latitude of origin. Differences among populations were significant for all traits in D. aldrichi $(P<0.001)$. Significant differences are indicated for D. buzzatii $(* P<0.05$, *** $P<0.001)$. 
from 1:1:1), and for direction of asymmetry, where for D. aldrichi, 14 were $\mathrm{R}>\mathrm{L}$ and $27 \mathrm{R}<\mathrm{L}\left(\chi_{(1)}^{2}=4.122\right.$, $P<0.05)$ and for D. buzzatii, 16 and eight, respectively (not significantly different from 1:1). For all traits, the numbers of significant deviations from zero mean were similar across populations, except for population 1 of D. aldrichi, with 13 significant deviations $(9 \mathrm{R}<\mathrm{L})$ involving seven traits, and all but two for flies raised at $20^{\circ} \mathrm{C}$.

For all traits, FA was less for D. aldrichi than for D. buzzatii, and less for males than for females. Temperature effects were more complex, with FA at a minimum for the linear traits at the intermediate temperature of $25^{\circ} \mathrm{C}$, but decreasing for wing area and increasing for wing shape and vein ratio as temperature increased.

\section{Discussion}

Body sizes of individuals from natural populations may give some indication of environmental conditions (temperature, nutritional stress) in the field and whether different species are differently affected by these conditions (Thomas, 1993). Although a smaller number of traits were significantly different among populations for D. aldrichi than for D. buzzatii (largely a function of the smaller numbers measured for the former), the observed patterns of trait size variation in relation to latitude in both species are similar, except for thorax length and wing loading index. The different patterns for the species at localities 1 and 2 (Fig. 2) are a result of the value for thorax length in D. buzzatii at locality 1 , where only one male and three females were measured. The mean thorax length of these females followed the pattern otherwise observed in this species and was longer than that for D. aldrichi from locality 1 , and the linear wing dimensions in D. buzzatii changed in proportion to those in D. aldrichi at locality 1 . Thus, the small thorax length of the single male $(\log \mathrm{TL}=2.934)$ was clearly aberrant. The linear size traits generally increased from north to south, as expected from the climatic differences among localities (van 't Land et al. 1999 for D. melanogaster), except that the natural populations of both species were smallest at locality 2 . This small size at locality 2 may be a consequence either of resource limitation resulting from locality-specific environmental conditions in the period prior to collection or the Opuntia host species at this locality, $O$. streptocantha, constituting a poorer resource than $O$. tomentosa, which was predominant at all other localities (Table 1). The latter explanation is unlikely as Krebs et al. (1992) found that the mean dry body weights of both Drosophila species emerging from $O$. streptocantha and $O$. tomentosa in laboratory cultures were not significantly different. However, locality 2 has the lowest average rainfall (Table 1), and in the 1-6 weeks prior to collection (when the collected flies were likely to be developing), only $4.6 \mathrm{~mm}$ rain was recorded at the nearest weather station (14 km distant) - a precipitation likely in $10 \%$ or fewer years. Under such dry conditions, rots would desiccate rapidly, so that resource limitation most likely explains the small size of the wild-caught flies of both species at this locality.

In the laboratory-reared flies, D. aldrichi from locality 2 again were exceptional in showing the generally smallest values for the linear traits, indicating that the small body size is genetic. These flies also showed faster development and higher viability than $D$. aldrichi from all other localities. For D. melanogaster, Nunney (1996) found that selection for short developmental time gave a correlated response of smaller body size. As $D$. aldrichi colonizes rots at a later stage than does $D$. buzzatii (Barker et al. 1984), and given the drier environment at locality 2, selection of this $D$. aldrichi population for shorter developmental time is most likely, and hence the genetically smaller body size.

Comparing wild-caught and laboratory-reared flies (Figs. 2 and 3), the latter were bigger for all linear traits in both species, despite lower average daily temperatures in the field $\left(22-24^{\circ} \mathrm{C}\right)$ in the weeks prior to collection, indicating poorer nutritional resources and/or greater competition for food resources in the field rots. However, wing shape (L3/W1) values were similar in wildcaught and laboratory-reared flies, while the wing loading index (L3/TL) and vein ratio $(\mathrm{L} 3 \mathrm{~d} / \mathrm{L} 3 \mathrm{p})$ were bigger in wild-caught flies. That is, under the nutritional stress in the field, the proportionate decreases are greater for TL than for L3, and greater for L3p than for L3d.

Factors other than nutritional resources (temperature, rainfall, etc. in the period prior to collection) could also affect the populations differentially. Similarly, genetic differences among populations (as inferred for locality 2) complicate interpretation. Restricting comparisons to those between nearest populations minimizes immediate weather effects, and in this case, the relative changes in L3p, L3d and vein ratio do indicate nutritional stress differences among the populations, with stress levels higher (particularly for D. aldrichi) at localities 2 and 4 . Between localities 3 and 4 , the pattern of change for the two species differed, with little change or a small increase in $D$. buzzatii and a decrease in $D$. aldrichi. That is, any increase in nutritional stress from locality 3 to locality 4 is greater for $D$. aldrichi than for D. buzzatii. Whereas at locality 2 , the greater stress on $D$. aldrichi seemed primarily a function of immediate weather conditions, this species difference at locality 4 could be a result of interspecific competition. Population numbers of both species were large at this locality (much less 
collecting effort), and the effect of D. buzzatii on the body size of $D$. aldrich $i$ is greater than that of $D$. aldrich $i$ on D. buzzatii (Krebs \& Barker, 1991). Thus the lack of any general latitudinal trend in the wild-caught flies would appear to be a result primarily of locality-specific environmental conditions.

In addition, however, the pattern of change across populations for $D$. aldrichi was very similar for the wildcaught and laboratory-reared flies, indicating that genetic differences among populations are greater in this species than in D. buzzatii. This is in accord with previous results showing much greater flight ability and dispersal potential for D. buzzatii (Gu \& Barker, 1995). Any possible latitudinal trend in $D$. aldrichi is apparently overshadowed by adaptation to local environmental conditions.

Populations of the two species from the same locality responded differently to laboratory conditions, such that variation with latitude of origin was significant for all traits in D. aldrichi (mainly a result of the small body size of population 2), but was not significant for thorax length, L2, L3p and area in D. buzzatii (Fig. 3). In neither species was there any trend for body size to increase with latitude, as was reported for D. melanogaster in South America (van t' Land et al. 1999) and Australia (James et al., 1995). However, clines in these studies of D. melanogaster spanned larger distances, and local habitat conditions in our study apparently do not vary linearly from north to south. This is particularly evident for $D$. aldrichi, which showed a latitudinal pattern similar to the natural populations, with population 2 smaller than the others.

In contrast to the data from the natural populations, variation among populations in body size for $D$. aldrichi, as well as variation in developmental time and viability, was much more pronounced than for D. buzzatii. Also, the population-temperature interaction was significant for more traits in $D$. aldrichi, i.e. this species showed higher plasticity. $\mathrm{CV}^{*}$ values were larger for all traits in D. aldrichi (as found also by Loeschcke et al., 1999), but FA values for all traits were less in $D$. aldrichi than in D. buzzatii, possibly indicating that $\mathrm{CV}^{*}$ values may be better general indicators for stress than FA (Woods et al., 1999). Viability is also lower in D. aldrichi than in D. buzzatii at all temperatures, except in flies from locality 2 , indicating that $D$. aldrichi generally is not as well adapted to the laboratory conditions as D. buzzatii, despite significantly higher FA values of $D$. buzzatii for L2 and W2. There is clear evidence for directional asymmetry of $D$. aldrichi raised at $20^{\circ} \mathrm{C}$, and particularly for the population originating from locality 1 , the most northerly location. It remains, however, unclear why these flies are left-handed, as $20^{\circ} \mathrm{C}$ does not seem to be a stressful temperature in itself. Fluctuating asymmetry in the natural populations also was lower in $D$. aldrichi than in D. buzzatii for all traits. It is unlikely that this observation can be explained by natural conditions being more stressful for $D$. buzzatii than for $D$. aldrichi.

Directions of change in wing length parameters with latitude of origin are often opposite in the two species, suggesting that laboratory conditions affect these two species very differently. Vein ratio increased with temperature in $D$. buzzatii but decreased in $D$. aldrichi (species $\times$ temperature, results not shown; Loeschcke et al., 1999). While the pattern of change in vein ratio with latitude is similar at all rearing temperatures in D. buzzatii, big differences in the direction of change occurred at different temperatures in D. aldrichi, showing that vein ratio is very temperature sensitive in D. aldrichi. Also for shape the significant species $\times$ population $\times$ temperature interaction reveals that latitude, as well as rearing temperature, have different effects on the wing shape of the two species.

Within each species, the patterns of change across populations for traits of the laboratory-reared flies fall into two groups (Fig. 3). One trait group consists of thorax length and the proximal length of the 3rd vein (L3p) and the other of the wing length parameters L2, L3 and the distal length of the 3rd vein (L3d). Wing width 2 follows the wing length trait group, as wing co-ordinate 6 apparently grows away from co-ordinate 2 proportional to wing length, whereas the wing width parameters $\mathrm{W} 1$ and $\mathrm{W} 3$ are more similar to thorax length, apparently as co-ordinates 3 and 6 are affected differently by temperature (Moreteau et al., 1998). These patterns of changes in traits actually hold for the same trait groups in both species, and thus must have a developmental basis. Furthermore, the association between the proximal length of the 3rd vein (L3p) and thorax length supports the view that the proximal part of this vein is more closely related developmentally to thorax length than to wing length (Loeschcke et al., 1999).

\section{Acknowledgements}

We are indebted to S. Brandt Bundgaard, A. Edmonds, N. Krug and J. Ross for technical assistance, and to R.E. Strauss and E. Dyreson, University of Arizona, Tucson, for providing the DIGITIZE and DISTANCE programs. The work was supported by a University of New England (UNE) Research Grant to JSFB, UNE Research Fellowships to VL and JB, a travel grant from the Danish Natural Sciences Research Council (SNF) to JB (grant no. 11-1135-1), and SNF grants to VL (grants no. 9701412 and 9700177) which also supported JSFB to work in Aarhus, where analyses and writing were completed. 


\section{References}

ATChley, W. R., GASKINS, C. T. AND ANDERSON, D. 1976. Statistical properties of ratios. I. Empirical results. Syst. Zool., 25, 137-148.

BARKER, J. S. F. AND KREBS, R. A. 1995. Genetic variation and plasticity of thorax length and wing length in Drosophila aldrichi and Drosophila buzzatii. J. Evol. Biol., 8, 689-709.

BARKER, J. S. F., EAST, P. D., PHAFF, H. J. AND MIRANDA, M. 1984. The ecology of the yeast flora in necrotic Opuntia cacti and of associated Drosophila in Australia. Microb. Ecol., 10, 379-399.

CAPY, P., PLA, E. AND DAVID, J. R. 1993. Phenotypic and genetic variability of morphometrical traits in natural populations of Drosophila melanogaster and D. simulans. I. Geographic variations. Génét. Sél. Évol., 25, 517-536.

CAVICCHI, S., GUERrA, D., NATAli, v., PEZZOLI, C. AND GIORGI, G. 1989. Temperature-related divergence in experimental populations of Drosophila melanogaster. II. Correlations between fitness and body dimensions. J. Evol. Biol., 2, 235-251.

DAVID, J. R. R., ALLEMAND, J., VAN HERREWEGE AND COHET, Y. 1983. Ecophysiology: abiotic factors. In: Ashburner, M., Carsons, H. L. and Thompson, J. N. (eds) The Genetics and Biology of Drosophila, Vol. 3d, pp. 105-170. Academic Press, London.

DAVID, J. R., MORETEAU, B., GAUTIER, J. P., PÉtAVy, G., STOCKEL, A. AND IMASHEVA, A. G. 1994. Reaction norms of size characters in relation to growth temperature in Drosophila melanogaster: an isofemale lines analysis. Génét. Sél. Évol., 26, 229-251.

DELPUECH, J.-M., MORETEAU, B., CHICHE, J., PLA, E., VOUIDIBIO, J. AND DAVID, J. R. 1995. Phenotypic plasticity and reaction norms in temperate and tropical populations of Drosophila melanogaster: ovarian size and developmental temperature. Evolution, 49, 670-675.

GU, H. AND BARKer, J. S. F. 1995. Genetic and phenotypic variation for flight ability in the cactophilic Drosophila species, D. aldrichi and D. Buzzatii. Ent. Exp. Appl., 76, 25-35.

JAMES, A. C., AZEvedo, R. B. R. AND PARTRIDGe, L. 1995. Cellular basis and developmental timing in a size cline of Drosophila melanogaster. Genetics, 140, 659-666.

JAMES, A. C. AND PARTRIDGE, L. 1995. Thermal evolution of rate of larval development in Drosophila melanogaster in laboratory and field populations. J. Evol. Biol., 8, 315-330.

KREBS, R. A. AND BARKER, J. S. F. 1991. Coexistence of ecologically similar colonising species: Intra- and interspecific competition in Drosophila aldrichi and D. Buzzatii. Aust. J. Zool., 39, 579-593.

KREBS, R. A., BARKER, J. S. F. AND ARMSTRONG, T. P. 1992. Coexistence of ecologically similar colonising species III. Drosophila aldrichi and D. buzzatii: larval performance on, and adult preference for, three Opuntia cactus species. Oecologia, 92, 362-372.

LOESCHCKE, V., BUNDGAARD, J. AND BARKER, J. S. F. 1999. Reaction norms across and genetic parameters at different temperatures for thorax and wing size traits in Drosophila aldrichi and D. Buzzatii. J. Evol. Biol., 12, 605-623.

MORETEAU, B., IMASHEVA, A. G., MORIN, J.-P. AND DAVID, J. R. 1998. Wing shape and developmental temperature in two Drosophila sibling species: different wing regions exhibit different norms of reaction. Russian J. Genet., 34, 183-192.

MORIN, J.-P., MORETEAU, B., PÉTAVY, G., PRAKASH, R. AND DAVID, J. R. 1997. Reaction norms of morphological traits in Drosophila: adaptive shape changes in a stenotherm circumtropical species? Evolution, 51, 1140-1148.

NIX, H. 1986. A biogeographic analysis of Australian elapid snakes. In: Longmore, R. (ed.) Atlas of Elapid Snakes of Australia, pp. 4-15. Australia Flora and Fauna series 7. Bureau of Flora and fauna, Canberra.

NUNNEY, L. 1996. The response to selection for fast larval development in Drosophila melanogaster and its effects on adult weight: an example of a fitness trade-off. Evolution, 50, 1193-1204.

PALMER, A. R. AND STROBECK, C. 1986. Fluctuating asymmetry: measurement, analysis, patterns. Ann. Rev. Ecol. Syst., 17, 391-421.

PARTRIDGE, L., BARRIE, B., FOWLER, K. AND FRENCH, V. 1994. Evolution and development of body size and cell size in Drosophila melanogaster in response to temperature. Evolution, 48, 1269-1276.

ROFF, D. A. AND MOUSSEAU, T. A. 1987. Quantitative genetics and fitness: lessons from Drosophila. Heredity, 58, 103-118.

SAS INSTITUTE 1985. SAS Procedures Guide for Personal Computers. SAS Institute, Inc, Cary, NC.

SAS INSTITUTE 1989. SAS/STAT User's Guide. SAS Institute, Inc, Cary, NC.

SOKAL, R. R. AND ROHLF, F. J. 1981. Biometry, 2nd edn. Freeman, San Francisco, CA.

STARMER, W. T. AND BARKER, J. S. F. 1986. Ecological genetics of the Adh-1 locus of Drosophila buzzatii. Biol. J. Linn. Soc., 28, 373-385.

STARMER, W. T., WOLF, L. L., BARKER, J. S. F., BOWLES, J. M. AND LACHANCE, M. A. 1997. Reproductive characteristics of the flower breeding Drosophila hibisci Bock (Drosophilidae) along a latitudinal gradient in eastern Australia: relation to flower and habitat features. Biol. J. Linn. Soc., 62, 459-473.

THOMAs, R. H. 1993. Ecology of body size in Drosophila buzzatii: untangling the effects of temperature and nutrition. Ecol. Entomol., 18, 84-90.

THOMAS, R. H. AND BARKER, J. S. F. 1993. Quantitative genetic analysis of the body size and shape of Drosophila buzzatii. Theor. Appl. Genet., 85, 598-608.

VAN 'T LAND. J. P., VAN PUTTEN, B., ZWAAN, A., KAMPING AND VAN DELDEN, W. 1999. Latitudinal variation in wild populations of Drosophila melanogaster: heritabilities and reaction norms. J. Evol. Biol., 12, 222-232.

WOODS, R. E., SGRÒ, C. M., HERCUS, M. J. AND HOFFMANN, A. A. 1999. The association between fluctuating asymmetry, trait variability, and stress: a multiply replicated experiment on combined stresses in Drosophila melanogaster. Evolution, 53, 493-505. 